\title{
Intertrial activity, awareness, and verbal conditioning of children
}

RODERICK WONG, JOANN HARRISON AND HELGA STOPPEK

UNIVERSITY OF BRITISH COLLUMIA

Seventy-five Grade 5 students were divided into three experimental and two control groups, and were required to construct sentences following the Taffel procedure. In the experimental groups, E said "good" whenever $S$ began a scntence with the pronoun "they". Three groups, two experimental and one control, received an intertrial activity (ITA): naming the colors of poker chips. One of the experimental ITA groups was reinforced before the ITA, and the other was reinforced after the ITA. A post-experimental interview was employed to assess awareness. The results indicate there was evidence for conditioning without awareness only when $S^{\prime}$ 's response to the Dixon $\delta$ Oakes (1965) type of intervicu was used for inferring awareness. When a more detailed and specific question was used as the basis for inferring aware ness, conditioning was seen to occur with awareness.

In an attempt to determine whether increments in verbal conditioning result from the automatic effects of reinforcement or from the mediating effects of awareness, Dixon \& Oakes (1965) studied the phenomenon by using the Taffel procedure along with the addition of intertrial activity (ITA). The ITA, which consisted of a color-naming task, was introduced in order to deprive Ss of an opportunity to formulate hypotheses about the reinforcement contingency involved in the Taffel task. The results indicated that the ITA group conditioned without being able to verbalize the reinforcement contingency when they were given a post-experimental interview.

The present experiment consists of a further study of the Dixon \& Oakes (1965) procedure with children rather than with college students. An additional condition was also introduced; one in which Ss were given reinforcement after rather than before color-naming activity.

\section{Method}

The Ss were 75 male and female students in their fifth grade at three elementary schools in Vancouver. They were assigned to five groups by a randomized procedure. One group received reinforcement prior to the ITA (R-ITA); another group received reinforcement following the ITA (ITA-R); and the third experimental group was reinforced in the typical manner following the correct response but was not given ITA (R). Two control groups were formed: one group received no reinforcement but was given ITA (ITA), while the other control consisted of Ss who were neither reinforced for their responses nor were given ITA (C).

The material for the conditioning trials consisted of 80 white index cards on each was typed a different verb in the simple past tense. The verbs were chosen from the Grade 5 Speller used in the Vancouver schools. The pronouns I, HE, SHE, WE, YOU, and THEY were typed in a row above each verb; the order in which these pronouns occurred was randomized over all cards. For the intertrial task poker chips which were either red, blue, yellow or white in color were used.

The usual instruction for the Taffel task was read to each $S$, and the order of the presentation of stimulus cards was randomized for each S. The IT $A$ groups were told to name the colors of the poker chips which would be shown to them between the sentence-forming tasks. Following their sentence, $E$ showed each $S$ in the ITA groups a poker chip which had been concealed behind a screen. The colors were varied with each presentation. For the non reinforced groups, E remained silent throughout the 80 trials. For Group R, E murmured "good"' whenever $S$ began his sentence with the pronoun "they." For Group R-ITA, E reinforced the "they" responses and immediately followed this with the presentation of poker chips which $S$ was required to name. For Group ITA-R, E reinforced the "they" responses after $\mathrm{S}$ had performed the ITA.

Upon completion of the 80 conditioning trials all Ss were interviewed. In order to facilitate comparison with the results of previous research, the first series of questions were of the same form as those used to evaluate "awareness" in the Dulany (1962) and the Dixon \& Oakes (1965) studies. These questions were:

1. Did you notice my saying anything during the experiment? (What?)

2. Did you think that I said it at any particular time? After something you did? (When?)

3. Why do you think I said "Good" in the experiment?

4. Did you do anything as a result of my saying "Good"?

5. How did you go about making up your sentences?

The Ss who were unable to verbalize the correct contingency with this set of questions received one further question:

6. If I told you that I said "Good" every time you used a certain pronoun, which pronoun would you say it was: I, HE, SHE, WE, YOU or THEY?

The responses of $S$ s to this series of questions were recorded, then tabulated for "awareness" or "nonawareness."

\section{Resulis}

The 80 trials were divided into four blocks of 20 trials each. A plot of the mean number of "they" responses made by each of the five groups is shown in Fig. 1. It can be seen that Ss in Groups R and R-ITA were superior in conditioning to any of the remaining groups. An analysis of variance of the number of correct responses made by $\mathrm{Ss}$ in the five groups during the last trial block 


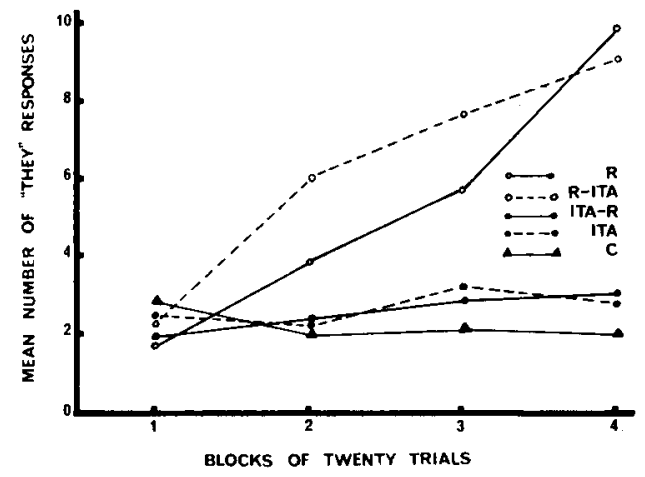

Fig. 1. Performance of the three experimental and the two control groups on four trial blocks.

indicated differences among the groups $(F=23.73$, $\mathbf{p}<.01)$. As expected, there was no difference between Groups $R$ and R-ITA $(t=0.66, p>.50)$, but multiple comparisons between these two and the remaining groups yielded Tukey's t-values which were significant at the .01 level. No differences were found among Groups C, ITA, and ITA-R at the .05 level.

The level of "awareness" of the reinforcement contingency for those in the three experimental groups was assessed by the Dixon and Oakes questions along with the additional one. If $S$ responded in the affirmative to any of these questions, he was classified as indicating "awareness." For Group R, 10 out of 15 Ss claimed to be "aware" on the first set of questions, and an additional two were found with the last question. With Group R-ITA, only three Ss were found with the first set, but eight more were revealed on the basis of the last question. In Group ITA-R, none of the Ss showed "awareness" on the first five questions, but three proved to be "aware" when they responded to the sixth question. The relationship between conditioning and "awareness" (on the basis of the full interview) when the data of Ss in the reinforced groups ( $R$ and R-ITA) were combined, is shown in Fig. 2.

\section{Discussion}

The finding that Groups $\mathrm{R}$ and R-ITA were similar in their level of conditioning provides support for the

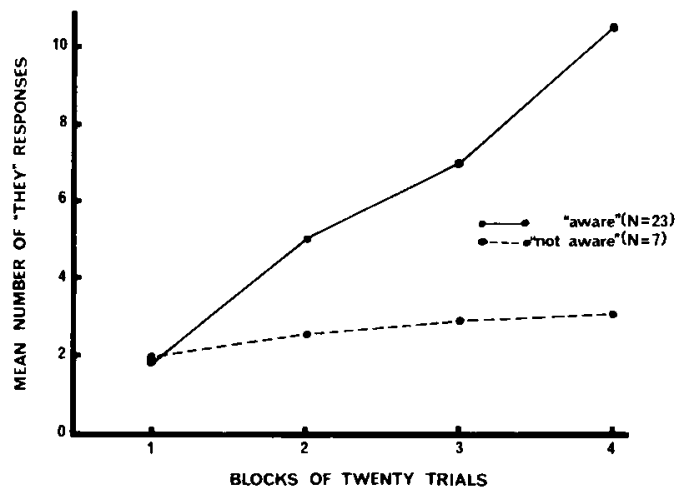

Fig. 2. Performance of "aware" and "unaware" subjects in Groups $R$ and R-ITA combined. previous results of Dixon \& Oakes (1965). Although most of the Group R Ss indicated awareness of the reinforcement contingency during the post-experimental interview, those in Group R-ITA showed almost no awareness according to their responses to these questions. However, in contrast to the Dixon \& Oakes (1965) results, there was some indication of awareness from Ss in Group R-ITA when they were required to respond to a more sensitive measure of awareness.

It has been suggested (Levin, 1961) that an $\mathrm{S}$ who is able to verbalize the contingency on a subsequent interview might have had the contingency suggested to him by some aspect of the interview. Our data suggest that the only Ss who showed verbal conditioning were those who were able to communicate the correct contingency. This finding implies that regardless of whether awareness is acquired independently or is "suggested" by the interview, verbalization of awareness is an essential aspect of verbal conditioning.

In this study, the intertrial activity, rather than preventing the formulation of hypotheses, as suggested by Dixon \& Oakes (1965), served only to interfere with the formulation of the correct hypothesis. For example, Ss in Group ITA-R all reported hypotheses, but these concerned the color-naming rather than the sentence forming task. This group, unlike Group R-ITA, did not report any awareness even when they were given the full interview. The R-ITA Ss, who very likely had two sets of hypotheses, one concerning the sentence task and the other concerning the color-naming task, were able to pin-point exactly which one of their hypotheses was the correct one when the nature of the contingency was more specifically outlined on the final interview item.

In general, the results of this study support the position that "what is learned in verbal conditioning is awareness of a correct response-reinforcement contingency" (Spielberger \& Levin, 1962). Furthermore, the results confirm Levin's (1961) hypothesis that the amount of awareness detected is a function of the sensitivity of the interview. In a study on the classical conditioning of meaning, Hare (1964) found that by using a more detailed method of assessing awareness, transfer of meaning occurred for only those Ss who could verbalize the contingency relationship. Such findings along with those in this study indicate the necessity of using detailed and specific items on the post-experimental questionnaire.

\section{References}

Dixon, P. W., \& Oakes, W. F. Effect of intertrial activity on the relationship between awareness and verbal operant conditioning. J. crp. Psychol., 1965, 69, 2, 152-159.

Dulany, D. E. The place of hypotheses and intentions: An analysis of verbal control in verbal conditioning. $J$. Pers., 1962, 30 , (Suppl.), 102-129.

Hare, R. D. Cognitive factors in transfer of meaning. Psychol. Rep., 1964, 15, 199-206.

Levin, S. M. The effects of awareness on verbal conditioning. J. exp. Psychol., 1961, 61, 57-75.

Spielberger, C. D., \& Levin, S. M. What is learned in verbal conditioning? J. verbal Learn. verbal Behav., 1962, 1, 125-132. 